\title{
Effects of red cell transfusion on cardiac output and blood flow velocities in cerebral and gastrointestinal arteries in premature infants
}

\author{
Mathias Nelle, Christina Höcker, Eugen P Zilow, Otwin Linderkamp
}

\begin{abstract}
Anaemia may increase the risk of tissue hypoxia in preterm infants. The effect of transfusion on circulation was studied in 33 preterm infants with a mean (SD) gestational age of 29 (5) weeks (range 26-34), birth weight 1153 (390) $\mathrm{g}$ (range 520-1840), and postnatal age of 48 (21) days (range 19-100). Packed cell volume, blood viscosity (capillary viscometer), cardiac output, and cerebral blood flow velocities in the internal carotid artery, anterior cerebral artery, and coeliac trunk (Doppler ultrasound) were determined before and after transfusion of $10 \mathrm{ml} / \mathrm{kg}$ of packed red blood cells. Transfusion increased packed cell volume from a mean (SD) $0.27 \quad(0.45)$ to $0.37 \quad(0.48)$. Mean arterial blood pressure did not change while heart rate decreased significantly from 161 (14) $1 / \mathrm{min}$ to 149 (12). Cardiac output decreased from $367(93) \mathrm{ml} / \mathrm{kg} / \mathrm{min}$ to 311 (74) due to decrease in stroke volume from $2 \cdot 28(0.57) \mathrm{ml} / \mathrm{kg}$ to $2 \cdot 14$ $(0.46)$ and in heart rate. There was a significant increase in systemic red cell transport (cardiac output times packed cell volume) by $17 \%$, systemic flow resistance (blood pressure to cardiac output ratio) by $23 \%$, and blood viscosity by $33 \%$. Vascular hindrance (flow resistance to blood viscosity ratio) did not change significantly, thereby suggesting that neither vasoconstriction nor vasodilation occurred with transfusion. After transfusion blood flow velocities decreased significantly in the anterior cerebral artery by $23 \%$, in the internal carotid artery by $8 \%$, and in the coeliac trunk by $12 \%$. Red cell transport estimated as products of blood flow velocities times packed cell volume increased significantly by $25 \%$ in the internal carotid artery and by $21 \%$ in the coeliac trunk. These results indicate that red cell transfusion improved systemic oxygen transport as well as oxygen transport in the internal carotid artery and coeliac trunk. (Arch Dis Child 1994; 71: F45-F48)
\end{abstract}

Many very low birthweight infants develop marked anaemia due to blood sampling, rapid growth, and insufficient erythropoiesis. ${ }^{1-3}$ Indications for red cell transfusions in preterm infants include replacement of blood losses, low packed cell volume values and clinical signs (for example, apnoeas, tachycardia, or growth failure) ${ }^{45}$ However, the critical lower limits of packed cell volume are not well defined and parameters clearly showing the benefits of red cell transfusion are lacking. Conflicting results have been reported as to whether blood transfusion results in changes of cardiac output. While Hudson et al found a reduction of cardiac output with transfusion, ${ }^{6}$ Alverson et $a l^{7}{ }^{7}$ and Bifano et al ${ }^{8}$ did not observe a significant change of cardiac output in premature infants. Rameakers et al showed that cerebral blood flow velocity in stable preterm infants decreases with transfusion according to the rise in oxygen supply. ${ }^{9}$ Studies on the effect of transfusion on blood flow in gastrointestinal arteries of preterm infants do not appear to exist in the literature.

The present investigation was designed to study the effect of blood transfusion on circulatory parameters in stable preterm infants who were 3 weeks or older at the time of study. A Doppler ultrasound device was used to determine cardiac output and blood flow velocities in cerebral arteries and in the coeliac trunk. Measurements of blood viscosity before and after transfusion were used to calculate the overall vessel geometry (that is, vascular hindrance).

\section{Patients and methods}

PATIENTS

Thirty three preterm infants with a mean (SD) gestational age of 29 (5) weeks (range 26-34), birth weight 1153 (390) g (range 520-1840), postnatal age 48 (21) days (range 19-100), and actual body weight 1935 (432) g (range 1000-2700) were studied with the approval of the ethical committee of the University Hospital of Heidelberg and with informed consent of the parents. At the time of investigation, all infants were in a stable clinical condition without respiratory or cardiac problems, signs of sepsis, or renal disease. Arterial blood gas values were: $\mathrm{pH} 7 \cdot 35-7 \cdot 45$, carbon dioxide tension $4 \cdot 7-6.0 \mathrm{kPa}$, and oxygen tension $8 \cdot 0-10 \cdot 7 \mathrm{kPa}$. They were not ventilated and not treated with sedatives, diuretics, or vasoactive drugs. The infants received $10 \mathrm{ml} / \mathrm{kg}$ of pure red blood cells over six hours. The blood had been taken two to five days before transfusion from the donors. Cardiovascular measurements were done before and four hours after transfusion.

Blood samples for determination of venous packed cell volume and blood viscosity $(2 \mathrm{ml}$ of 
antecubital blood) were collected before and four hours after transfusion. Excessive squeezing and prolonged tourniquet application were avoided. The blood samples were taken after the cardiovascular measurements had been done.

\section{HAEMATOLOGICAL METHODS}

Packed cell volume was measured in duplicate by the microhaematocrit method. The values were corrected for $2 \%$ of trapped plasma. Red blood cell count, haemoglobin concentration, and white cell count were determined using a cell counter (Contraves). Blood viscosity was measured within one hour after blood collection using a capillary viscometer. ${ }^{10}$

\section{CIRCULATORY PARAMETERS}

The cardiovascular examinations were made at least an hour after previous feeding. Measurements were done when the infants were in a quiet sleep state. Quiet sleep was assumed when infants eyes were closed, no movements were observed apart from occasional stable reactions and respiration was regular. The infants were in the supine position. Blood flow velocities and cardiac output were measured using an Interspec XL pulsed Doppler ultrasound system (Interspec Inc) as previously described. ${ }^{11}$ The aortic valve annulus was visualised by $\mathbf{M}$ mode echocardiography using the parasternal long axis view, and the aortic diameter was measured by the leading edge method from the anterior aortic wall to the anterior boundary of the posterior aortic wall in late diastole over five consecutive cycles. Aortic cross sectional area was calculated in late diastole as $\pi \times r^{2}$, where $r$ represents the annular radius averaged over five consecutive cycles. From an apical four chamber view, the pulsed Doppler sample volume was placed at the level of the aortic valve annulus. ${ }^{11}$ Aortic velocity integrals were recorded with a mechanical $5.0 \mathrm{MHz}$ transducer using the duplex mode in an attempt to obtain the fastest spectral envelopes. Doppler wave forms were analysed by the software of the ultrasound system for peak velocity, mean velocity, and average time velocity integral. ${ }^{12} 13$ Cardiac output was calculated as the product of stroke volume and heart rate. Cardiac index was calculated as the ratio of cardiac output:actual body weight.

Cerebral blood flow velocities in the anterior cerebral artery and right and left internal carotid artery were measured using a $5.0 \mathrm{MHz}$ pulsed Doppler transducer from a coronal scan via the anterior fontanelle. The arteries were identified by duplex scan mode. ${ }^{14}$ There were no significant differences between the two internal carotid arteries. Therefore, only the results of the right carotid artery are shown.

The coeliac trunk was localised by ultrasound from a longitudinal abdominal section. Blood flow velocity in the coeliac trunk was determined close to the origin of the artery from the abdominal aorta. The direction of the blood flow in this region is directed towards the transducer. There was no significant angle of insonance between the Doppler beam and the coeliac artery. Angle corrections of velocities were made in all cases.

In all vessels the system software was used to calculate maximal systolic, maximal end diastolic, and mean average flow velocity. The average of five consecutive, homogeneous flow cycles was taken in all measurements after 60 constant flow velocity integrals were recorded. When beat-to-beat coefficient of variation was less than $5 \%$, Doppler recordings were taken as stable.

In 12 infants cardiac output, cerebral and intestinal flow velocities were determined twice within one hour to estimate intraobserver variability of these parameters. Intraobserver variability was $9.8 \%$ for cardiac output, $6.5 \%$ for cerebral and $10.6 \%$ for intestinal blood flow velocities. To eliminate interobserver variability, all measurements were done by one person $(\mathrm{CH})$.

\section{MISCELLANEOUS METHODS}

Mean arterial blood pressure was measured in the right and left upper arm using an oscillometric technique (Dinamap 847, Critikon). Some infants woke up during blood pressure measurements so that we cannot rule out that blood pressure increased in these infants. Systemic flow resistance (R) was calculated as mean pressure $(P)$ to cardiac output ratio $(\mathrm{Q}=$ flow $)$. According to the Hagen-Poiseuille law the flow resistance in a single vessel depends on blood viscosity $(\eta)$, vessel length $(\mathrm{L})$, and vessel radius $(\mathrm{r})$ :

$$
\mathrm{R}=\frac{\mathrm{P}}{\mathrm{Q}}=\frac{8}{\pi} \times \frac{\mathrm{L}}{\mathrm{r}^{4}} \times \eta=\mathrm{Z} \times \eta
$$

$\mathrm{Z}=(8 / \pi) \times\left(\mathrm{L} / \mathrm{r}^{4}\right)$ is the vascular hindrance and expresses the effect of the vessel geometry on the flow resistance. ${ }^{15} \mathrm{Z}$ can be calculated as resistance:viscosity ratio. $Z$ increases as a result of vasoconstriction and decreases with vasodilation. Although the Hagen-Poiseuille law is valid only for single circular vessels, $Z$ can also be used as an indicator of overall vasoconstriction when serial studies in the same persons are performed. ${ }^{15}$

As an index of red cell transport, the product of mean flow velocity, and peripheral venous packed cell volume was calculated. Systemic red cell transport was calculated as product of cardiac output and packed cell volume.

\section{STATISTICAL ANALYSIS}

A two tailed paired $t$ test was done to test for differences in the measurements before and 4 hours after blood transfusion; $\mathrm{p}<0.05$ was considered significant. Data are presented as mean (SD).

\section{Results}

Changes in haemodynamic and rheological variables after transfusion are shown in the 
Effect of red cell transfusion on circulatory and rheology parameters; values are mean (SEM)

\begin{tabular}{|c|c|c|c|c|}
\hline & $\begin{array}{l}\text { Before } \\
\text { transfusion }\end{array}$ & $\begin{array}{l}\text { After } \\
\text { transfusion }\end{array}$ & Difference & $\stackrel{p}{\text { Value }}$ \\
\hline Packed cell volume (PCV) & $0.27(0.045)$ & $0.37(0.048)$ & $0.1(0.04)$ & 0.001 \\
\hline Haemoglobin $(g / 1)$ & $8.8(1.5)$ & $12 \cdot 2(1 \cdot 7)$ & $3.4(0.3)$ & 0.001 \\
\hline Mean blood pressure $(\mathrm{P}, \mathrm{mm} \mathrm{Hg})$ & $56.4(7.9)$ & $58 \cdot 1(7 \cdot 9)$ & $1.7(1.5)$ & NS \\
\hline Heart rate (beats/min) & $161(14)$ & $149(12)$ & $12(3)$ & 0.005 \\
\hline Cardiac output (CO, $\mathrm{ml} / \mathrm{kg} / \mathrm{min})$ & $367(93)$ & $311(74)$ & $56(16)$ & 0.005 \\
\hline Stroke volume $(\mathrm{ml} / \mathrm{kg})$ & $2.28(0.57)$ & $2 \cdot 14(0.46)$ & $0.14(0.07)$ & 0.05 \\
\hline Blood viscosity $(\eta, \mathrm{mPa} / \mathrm{s})$ & $1.8(0.3)$ & $2.4(0.4)$ & $0.6(0.05)$ & 0.001 \\
\hline Flow resistance $\left(\hat{R}=10^{3} \times P / C O\right)$ & $160(5)$ & $196(6)$ & $36(10)$ & 0.005 \\
\hline Vascular hindrance $(R / \eta)$ & $90 \cdot 6(27 \cdot 2)$ & $82 \cdot 6(26 \cdot 4)$ & $8(5 \cdot 3)$ & NS \\
\hline \multicolumn{5}{|l|}{ Mean blood flow velocity $(\mathrm{m} / \mathrm{sec})$} \\
\hline Internal carotid artery & $0.24(0.06)$ & $0.22(0.05)$ & $0.02(0.01)$ & 0.05 \\
\hline Anterior cerebral artery & $0.26(0.11)$ & $0.20(0.06)$ & $0.06(0.02)$ & 0.05 \\
\hline Coeliac trunk & $0.34(1 \cdot 3)$ & $0.30(0.09)$ & $0.04(0.02)$ & 0.05 \\
\hline \multicolumn{5}{|l|}{ Systemic red cell transport } \\
\hline (CO $\times$ PCV) & $99 \cdot 1(32 \cdot 5)$ & $115 \cdot 9(22 \cdot 7)$ & $16 \cdot 8(3 \cdot 9)$ & 0.005 \\
\hline \multicolumn{5}{|l|}{ Red cell transport } \\
\hline Internal carotid artery & $6 \cdot 5(1.9)$ & $8 \cdot 1(2 \cdot 0)$ & $1.6(0.4)$ & 0.005 \\
\hline Anterior cerebral artery & $7 \cdot 0(2 \cdot 2)$ & $7 \cdot 4(2 \cdot 7)$ & $1.4(0.3)$ & NS \\
\hline Coeliac trunk & $9 \cdot 2(3 \cdot 4)$ & $11 \cdot 1(3 \cdot 0)$ & $1.9(0.4)$ & 0.005 \\
\hline
\end{tabular}

table. After transfusion of $10 \mathrm{ml} / \mathrm{kg}$ of pure red cells packed cell volume increased by $0 \cdot 10$. Cardiac output decreased by $15 \%(\mathrm{p}<0.005)$, due to decreases in heart rate by $7 \%(\mathrm{p}<0.05)$ and stroke volume significantly by $6 \%$ $(\mathrm{p}<0.005)$. Mean arterial blood pressure did not change. Systemic red cell transport (cardiac output times packed cell volume) increased significantly by $17 \% \quad(p<0 \cdot 05)$. Systemic flow resistance (blood pressure to cardiac output ratio) increased by $23 \%$ $(p<0.05)$ and blood viscosity increased by $33 \% \quad(p<0.001)$. Vascular hindrance (flow resistance to blood viscosity ratio) did not change significantly after transfusion.

Blood flow velocities decreased significantly in the internal carotid artery by $8 \%(p<0.05)$, in the anterior cerebral artery by $23 \%$ $(p<0.005)$, and in the coeliac trunk by $12 \%$ $(p<0.05)$ with transfusion. Red cell transport estimated as product of blood flow velocity times packed cell volume increased significantly by $25 \%(\mathrm{p}<0.05)$ in the internal carotid artery and by $21 \%(\mathrm{p}<0.005)$ in the coeliac trunk. In the anterior cerebral artery red cell transport did not change significantly with transfusion.

\section{Discussion}

Anaemia may predispose the preterm infant to tissue hypoxia because of reduced oxygen carrying capacity of the blood. The results of the present study show that in 3 to 14 week old preterm infants red cell transfusion decreased cardiac output due to decreases in heart rate and stroke volume suggesting that the heart rate before transfusion was increased in response to the anaemia. ${ }^{16}$ As the rise in packed cell volume was more pronounced than the fall in cardiac output, systemic red cell transport (packed cell volume times cardiac output) increased significantly. Hudson et al found a decrease in cardiac output by $12 \%$ and a rise in red cell transport by $30 \%$ after transfusion of $20 \mathrm{ml} / \mathrm{kg}$ of red cells in preterm infants with 2 to 90 days of age. ${ }^{6}$ Alverson $e t ~ a l^{7}$ and Bifano et al 8 found no significant change in cardiac output, but a rise in systemic red cell transport by about $25 \%$.
Red cell transport in cerebral arteries showed a marked rise in the internal carotid artery $(+25 \%)$ with transfusion, but no significant change in the anterior cerebral artery. Assuming that the blood flow velocities in cerebral arteries reflect the actual blood flows, ${ }^{17}$ this suggests that the overall oxygen transport to the brain was improved by transfusion, but with marked regional variations. In particular, the brain tissue supplied by the anterior cerebral artery does not appear to benefit from red cell transfusion. Rameakers et al studied the effect of transfusion on blood flow velocity in the pericallosal artery of preterm infants and found also no change in red cell transport. ${ }^{9}$

Studies on the effect of transfusion on the blood flow velocity in the cerebral artery media of preterm infants do not appear to exist in the literature.

We observed a significant decrease $(-12 \%)$ in blood flow velocity in the coeliac trunk and a rise in red cell transport $(+21 \%)$. In newborn piglets, transfusion of $25 \mathrm{ml} / \mathrm{kg}$ of blood decreased cardiac output and gastrointestinal blood flow by $10 \%$, whereas systemic and gastrointestinal red cell transport did not change. ${ }^{18}$

As the arterial blood pressure did not change with transfusion, systemic vascular resistance (pressure to cardiac output ratio) increased after transfusion according to the decrease in cardiac output (table). Flow resistance increases with increasing vascular hindrance (that is, increasing vasoconstriction) and increasing blood viscosity. ${ }^{15}$

In our study, red cell transfusion resulted in a marked rise of blood viscosity whereas vascular hindrance did not change. This suggests that red cell transfusion did not change overall vessel geometry in the preterm infants.

We conclude that red cell transfusion improves the overall systemic red cell transport as well as the red cell transport in cerebral and gastrointestinal arteries.

This study was supported by a grant from the German Research Council (Deutsche Forschungsgemeinschaft; Project Li 291/43 ). The authors thank the nurses of the neonatology division for their cooperation and Vivian M Vargas, MSBA, for her help in preparing the manuscript.

1 Stockmann J. The anemia of prematurity and the decision when to transfuse. Adv Pediatr 1984; 31: 191-219.

2 Holland BM, Jones JG, Wardrop CAJ. Lessons from the anemia of prematurity. Hematol Oncol Clin North Am 1987; i: 882-4.

3 Obladen M, Sachsenweger M, Stahnke M. Blood sampling in very low birth weight infants receiving levels of intensive care. Eur f Pediatr 1988; 147: 399-404.

4 Ross MP, Christensen RD, Rothstein G, et al. A randomized trial to develop criteria for administering erythrocyte transfusions to anemic preterm infants 1 to 3 months of age. $\mathcal{F}$ Perinatol 1989; 9: 246-53.

5 Meyer J, Sive A, Jacobs P. Empiric red cell transfusion in asymptomatic preterm infants. Acta Paediatr Scand 1993; 88: $30-4$.

6 Hudson I, Cooke A, Holland B, et al. Red cell volume and cardiac output in anaemic preterm infants. Arch Dis Child 1990; 65: $672-5$.

7 Alverson DC, Isken VH, Cohen RS. Effect of booster blood transfusions on oxygen utilisation in infants with transfusions on oxygen utilisation in infants with

8 Bifano EM, Smith F, Borer J. Relationship between determinants of oxygen delivery and respiratory abnormalities in nants of oxygen delivery and respiratory abnormalities in
preterm infants with anemia. F Pediatr 1992; 120: 292-6.
Rameakers VT, Casaer P, Marchal G, Smet M, Goossens W. 9 Rameakers VT, Casaer P, Marchal G, Smet M, Goossens W. The effect of blood transfusion on cerebral blood-flow in
preterm infants. Dev Med Child Neurol 1988; 30: 334-41. 10 Nelle M, Kraus M, Zilow EP, Bastert G, Linderkamp O. The effect of Leboyer delivery on blood viscosity and 
other hemorheologic parameters in term neonates. Am $\mathcal{F}$ Obstet Gymecol 1993; 169: 189-93.

11 Mandelbaum-Isken VH, Linderkamp O. Cardiac output by pulsed Doppler in neonates using the apical window. Pediatr Cardiol 1991; 12: 13-6.

12 Takenaka K, Waffarn F, Dabestani A, Gardin JM, Henry WL. A pulsed Doppler echocardiographic study of postnatal changes in pulmonary and ascending aortic flow in normal term newborn infants. Am Heart $\mathcal{f} 1987$; 113: normal

13 Lewis JF, Lawrenz CK, Nelson JG, Simacher MC, Quionones M. Pulsed Doppler echokardiographic determination of stroke volume and cardiac output: clinical validation of two methods using the apical window. Circulation 1984; 70: 425-31.

14 Deeg KH, Rupprecht T. Pulsed Doppler sonographic measurement of normal values for the flow velocities in the intracranial arteries of healthy newborns. Pediatr Radiol 1989; 19: 71-8.

15 Fan FC, Chen RYZ, Schuessler GB, Chien S. Effects of hematocrit variations on regional hemodynamics and oxygen transport in the dog. Am f Physiol 1980: 238: H545-52.

16 Wardrop CAJ, Holland BM, Veale KEA, et al. Nonphysiological anaemia of prematurity. Arch Dis Child 1978; 53: 855-60.

17 Greisen G, Pryds Ole, Rosén I. Lou H. Poor reversibility of EEG abnormality in hypotensive, preterm neonates. Acta Pediatr Scand 1988; 77: 785-90.

18 Novicki PT, Hansen NB, Stonestreet B, Yao AC, Oh W. The effect of blood volume expansion on gastrointestinal oxygenation in piglets. Pediatr Res 1985; 19: 268-71. 